\title{
Tidal forced expirations
}

\author{
P.D. Sly*, R. Tepper**, M. Henschen***, M. Gappa ${ }^{\#}$, J. Stocks ${ }^{+}$, on behalf of the ERS/ATS \\ Task Force on Standards for Infant Respiratory Function Testing
}

Tidal forced expirations. P.D. Sly, R. Tepper, M. Henschen, M. Gappa, J. Stocks, on behalf of the ERS/ATS Task Force on Standards for Infant Respiratory Function Testing. (C)ERS Journals Ltd 2000.

ABSTRACT: The progress of infant lung function testing has been retarded by both the lack of user-friendly, widely available and affordable equipment and the lack of standardized methodology. The European Respiratory Society/American Thoracic Society Task Force on Standards for Infant Respiratory Function Testing was formed in an attempt to address these deficiencies. This document represents the consensus of investigators with vast experience in the measurement of lung function in infants. The present recommendations deal with equipment requirements, study procedures and reporting of data for measurements of forced expiration at end-tidal inspiration. They represent the "state of the art" in 1999. They are not meant to inhibit further developments in this technique. The authors anticipate that these guidelines will be updated regularly as knowledge progresses.

Eur Respir J 2000; 16: 741-748.
*Division of Clinical Sciences, TVW Telethon Institute for Child Health Research, Dept of Paediatrics, University of Western Australia, Princess Margaret Hospital for Children, Perth, Australia. **Section of Pediatric Pulmonology, Indiana University Medical Center, James Whitcomb Riley Memorial Hospital for Children, Indianapolis, IN, USA. ***Universitaets-Kinderklinik Mathildenstrasse, Freiburg, Germany. "Medizinische Hochschule, Kinderklinik, Hanover, Germany. ${ }^{+}$Portex Anaesthesia, Intensive Therapy and Respiratory Medicine Unit, Institute of Child Health, London, UK.

Correspondence: P.D. Sly, Division of Clinical Sciences, TVW Telethon Institute for Child Health Research, P.O. Box 855, West Perth, Western Australia 6972, Australia. Fax: 61894897706

Keywords: Forced expiration, infant lung function testing, standardization

Received: August 171999 Accepted after revision March 192000

This work was supported by a grant from the European Respiratory Society, and by donations from Glaxo-Wellcome (UK) and Glaxo-Wellcome AB (Sweden).
The present document represents one of a series that is being produced by the European Respiratory Society/ American Thoracic Society Task Force on Standards for Infant Respiratory Function Testing. The aim of this task force is to summarize what is currently seen to be good laboratory practice, and to provide recommendations for both users and manufacturers of infant lung function equipment and software. These recommendations have been developed after widespread communication on an international level and are directed towards future developments in this field, including the use of more automated and standardized equipment than has been used in many clinical and research centres in the past.

\section{For editorial comments see page 583.}

It is important to emphasize that the recommendations presented here do not invalidate previously published data collected with less automated systems or without all the quality control suggested within. It is recognized that this document will need regular updating in response to advances in both technology and knowledge regarding the application and interpretation of these tests under different circumstances. In the meantime, every attempt has been made to avoid being too prescriptive in order to allow for future developments, while at the same time offering guidance as to minimum standards for those developing equipment and performing tests.

In view of the relatively recent introduction of measurement of forced expiration at raised lung volume, and continuing controversies with respect to methodology, analysis and reporting of results, the recommendations in the current document have been limited to the tidal rapid

Previous articles in this Series: No. 1: Frey U, Stocks J, Coates A, Sly PD, Bates J, on behalf of the ERS/ATS Task Force on Standards for Infant Respiratory Function Testing. Specifications for equipment used for infants pulmonary function testing. Eur Respir J 2000; 16: 729-738. 
thoracoabdominal compression (RTC) technique. It is called this in order to distinguish it from measurements made at raised lung volumes or other techniques for producing forced expiration, and is principally used to measure the maximal flow at functional residual capacity (FRC) that can be produced by forced expiration from endtidal inspiration ( $\left.V^{\prime} \max , \mathrm{FRC}\right)$. Further practical details of how to apply this technique and interpret the results have been described previously [1-10]. The task force has published a book that collates much of the relevant information and discusses background issues that may influence the measurements $[4,6]$. Further details regarding equipment and software specifications can be found in the papers of FreY et al. [11] and BATES et al. [12], which form part of the present series.

A subsequent document dealing with the special issues arising when using the raised volume technique will be developed once a greater degree of consensus has been reached. Similarly, the use of the tidal RTC and other techniques to assess airway reactivity, whether by means of bronchodilation or bronchial challenge tests, will be the subject of separate documentation.

It is anticipated that acceptance and application of these recommendations will be of particular value when attempting to compare data between centres, develop or use reference data or participate in multicentre trials which use parameters of infant respiratory function as outcome measures.

\section{Equipment}

See also the documents described equipment and software specifications $[11,12]$ and tidal breathing analysis [13] in the present series for further details and justification of the recommendations presented below.

\section{Face mask}

Different types of mask are used in different parts of the world, based largely on local preference and availability. In order to aid international standardization the following recommendations are made. 1) the brand and size of mask should be reported. (e.g. Rendell Baker size $0,1,2$ or 3 ). 2) dead space should be minimized. Report whether measures to reduce mask volume are used (e.g. silicon putty). 3) measure the dead space of the mask by means of water displacement and subtract $50 \%$ of this value to estimate the effective dead space [12]. This recommendation is based on expert opinion and bench tests rather than on hard evidence gained from physiological measurements of dead space with apparatus in situ.

\section{Flowmeter}

This should be a low-resistance low-dead space device with a linear range appropriate to the age of infant studied and flows likely to be encountered (linearization by software is acceptable) (table 1) $[6,12]$. It is recognized that several new potentially valuable devices (e.g. ultrasonic) are currently being developed and validated for use in infant respiratory function measurements. However, since
Table 1. - Range of flows likely to be encountered during infant rapid thoracoabdominal compression (RTC) studies* $^{*}$

\begin{tabular}{lcc}
\hline & \multicolumn{2}{c}{ Flow range $\mathrm{mL} \cdot \mathrm{s}^{-1}$} \\
\cline { 2 - 3 } $\begin{array}{l}\text { Infant weight } \\
\mathrm{kg}\end{array}$ & $\begin{array}{c}\text { Tidal } \\
\text { breathing }\end{array}$ & $\begin{array}{c}\text { Tidal } \\
\text { RTC }\end{array}$ \\
\hline$<2$ & $0-100$ & $0-200$ \\
$2-4$ & $0-200$ & $0-500$ \\
$4-10$ & $0-300$ & $0-1000$ \\
$10-15$ & $0-500$ & $0-1500$ \\
\hline
\end{tabular}

*: ranges refer to the highest peak flows likely to be encountered during testing in healthy infants $[6,12]$. In sick infants and those with any evidence of flow limitation, flows will be much lower, especially at functional residual capacity, and the pneumotachometer should be selected accordingly.

the pneumotachometer (PNT) is currently the most commonly used device, this will generally be referred to in this document. 1) If a PNT is used, it should be heated to body temperature to avoid condensation on the resistive element. 2) Since brief airway occlusions may be used to test both the absence of leaks and the efficacy of mean jacket inflation pressure $\left(P_{\mathrm{j}}\right)$ transmission (see Measurement of efficacy of jacket pressure transmission section), the system should be checked to ensure that pressurization of the PNT does not influence the flow/volume data obtained [6]. In an attempt to avoid gas compression/ decompression artefacts, the PNT is not positioned between the face mask and the occlusion valve in some systems. However, providing the flow transducer is perfectly balanced, gas compression may not be a problem.

\section{Pressure transducers}

1) The maximum range of airway opening pressure likely to be encountered is $0-5 \mathrm{kPa},\left(50 \mathrm{cmH}_{2} \mathrm{O}\right)$ during static pressure transmission checks during the tidal RTC (see Measurement of efficacy of jacket pressure transmission section). 2) The maximum applied jacket pressures are $\sim 10-12 \mathrm{kPa}\left(100-120 \mathrm{cmH}_{2} \mathrm{O}\right)$; transducers, therefore, need to record $0-15 \mathrm{kPa}\left(0-150 \mathrm{cmH}_{2} \mathrm{O}\right)$ accurately. 3) The accuracy and linearity of the pressure transducers should be checked regularly using an electronic manometer [11].

With modern solid-state transducers, the same type of transducer may be adequate for both airway opening and $P$. This also has the advantage of making phase matching easier.

Jacket

The jacket used for producing the RTC consists of two parts: an inflatable component that is positioned against the infant's anterior chest wall and upper abdomen and an outer nonexpansile component that wraps around the infant. The jacket, including the inflatable inner bladder, should be designed to cover as much of the chest and upper abdomen as possible. This means that three or four sizes are likely to be needed to cover the wide range of infant size $(2-4,4-8,4-12$ and $>12 \mathrm{~kg}$ (if preschool children are 
to be studied)). The jacket needs to be fully adjustable, ideally with some silent means of being fastened securely. Although Velcro has been widely used in the past, the noise occurring on unfastening this often disturbs the infant. The insertion of a separating zipper in the nonexpansile outer layer of the jacket has been found to be very useful for loosening the jacket during other tests, or if the jacket needs to be removed rapidly.

The jacket pressure must be measured as close to the jacket as possible.

Rate of rise of jacket pressure. The rate of rise of jacket pressure is determined by the speed of opening of the valve connecting the pressure source to the jacket and the bore of the connecting tubing. The rate of rise of airway opening pressure (when the jacket is inflated against a closed airway; see Measurement of efficacy of jacket pressure transmission section) is determined by the rate of rise of pressure within the jacket, how snugly the jacket is wrapped around the chest wall and the compliance of the chest wall.

Recommended valve opening speed. Ideally this should occur within $10 \mathrm{~ms}$ (maximum $20 \mathrm{~ms}$ ).

Recommended speed of pressure transmission to airway opening. Pressure should be transmitted rapidly to the airway opening, taking $\sim 100 \mathrm{~ms}$ to reach $95 \%$ of final pressure.

\section{Pressure source}

A drum of $\sim 50$-L capacity has been used to inflate the jacket, although there are other possible methods [4].

Essential features. 1) The material the drum is made from is not critical; however, it must be able to withstand pressures of up to $45 \mathrm{kPa}$ without rupture. It should be noted that plastic drums will have some elasticity, but this does not interfere with their function. 2) The drum is usually filled from a pressurized wall source or other suitable compression source (pressures up to $400 \mathrm{kPa}$ ). A pressure regulation system is necessary to ensure that the drum is not exposed to these pressures. 3) A pressure relief valve is required to ensure that the pressure in the drum is not accidentally increased too much. This should be set to blow off at pressures somewhat above the maximum pressure required to inflate the jacket (e.g. $\sim 12-15 \mathrm{kPa}) .4)$ A clear display of pressure within the drum (assessed using a suitable sensor) should be available to the operator at all times. Ideally, both the set pressure and the pressure attained should be displayed. 5) The drum should inflate the jacket through rigid wide-bore tubing (e.g. reinforced 35-mm inside diameter tubing).

\section{Valves}

The following valves are required: 1) a valve to occlude the airway opening if jacket transmission pressure is being assessed statically during brief airway occlusions (in the past some have performed this manually), 2) a valve to fill the jacket from the pressure source, 3 ) a valve to empty the jacket to atmosphere, 4) a valve to isolate the drum from the filling pressure source, 5) valves to control maskflushing flow of air or oxygen (optional; alternatively, some systems have used a separate opening to facilitate flushing the mask). 2) The connections from pressure source to drum and drum to jacket must be arranged so that they can never be open simultaneously! This must be secured electronically, rather than by reliance on software. 3) The guiding principle should be that any valve that is directly connected to the patient's airway should default to the open position and valves separating the patient from pressure sources (e.g. to and from the drum) should default to the closed position if the power fails. The incorporation of an electronic switch that can be manually activated by the operator to activate jacket deflation and/ or open the airway opening valve could be a useful additional safety measure. 4) Timing co-ordination is required between the valves, e.g. so that the airway opening valve can be closed at end-inspiration while the jacket is filling (required for static-transmission manoeuvre; see Measurement of efficacy of jacket pressure transmission section). This procedure can also be used during forced expiratory manoeuvres, in which occluding the airway at endinspiration can cause respiratory muscles to relax by inducing the Hering-Breuer reflex and ensure that lung volume does not decrease during the time required for jacket inflation.

\section{Data acquisition}

Data acquisition requirements are dealt with elsewhere in this series $[11,12]$. Four particular points of relevance to the RTC are: 1) the recommended sampling rate for acquisition of RTC data is $200 \mathrm{~Hz}$. 2) Inspired flows and volumes must be converted to body temperature and ambient pressure and saturated with water vapour (BTPS) conditions. It is assumed that the expired gas, as used in the calculation of $V^{\prime} \max , \mathrm{FRC}$, is at BTPS conditions. 3) Any drift of the tidal volume signal prior to the forced expiratory manoeuvres should be minimized. 4) A representative end-expiratory level (EEL) must be established (see Calculations section).

\section{Monitor display}

See also the articles of FREY and coworkers [11, 12]. 1) During data collection and/or replay, real time displays of volume, $P \mathrm{j}$ and airway opening pressure are required, together with the flow/volume curve. 2) Selected flow/ volume curves should be stored on screen for subsequent reference. During the test, the operator should have the ability to determine whether the current curve replaces the previous ones (i.e. the screen is refreshed and the new curve replaces the old ones) or is added to the curves already displayed (i.e. the new curve is overlaid on the previous curves). 3) The ability to overlay curves (e.g. up to the last one or a selected three to five), on screen needs to be an option within the software. The issue of how/ where to overlay curves, i.e. along the descending "flowlimited" portion or at end inspiration, remains the subject of debate. However, it should be noted that overlay at end expiration is unlikely to be satisfactory in view of the 
marked variability of EEL in many infants. 4) The ability to move a cursor along the flow/volume curve, reading off both flow and volume, would also be highly desirable, together with user flexibility to adjust the computerselected EEL if needed. 5) The ability to reject a curve before storage is required, together with the ability to exclude (but not delete) selected trials during the analysis process, should also be available.

\section{Measurement protocol}

\section{Posture}

Measurements should be made with 1) the infant lying supine; and 2) the neck and/or shoulders supported in the midline in slight extension; the position is stabilized using a neck roll or head ring. Preparation for data collection using the tidal rapid
thoracoabdominal compressoin (squeeze) technique

1) The infant should be wrapped in a suitably sized jacket. 2) Most studies are currently performed with the arms outside the jacket [15]. In cases in which the arms are wrapped inside the jacket, this should be explicitly reported. 3) The outer nonexpansile part of the jacket should be firmly wrapped, while still being able to insert two adult fingers between the inner inflatable part of the jacket and the infant's sternum. 4) The jacket should not impede chest wall movement during tidal breathing. $P \mathrm{j}$ should remain zero throughout the breathing cycle, as can be checked from a time-based display after amplifying the signal. The recording of any $P \mathrm{j}$ signal prior to jacket inflation means that the jacket is too tight. However, even in the absence of such evidence, the jacket may influence chest wall compliance and lung volume, and it is, therefore, recommended that it be loosened prior to measuring other parameters of infant respiratory function, especially any parameter measured from a raised volume. 5) If the mask is to be left in situ during a protocol, assessment of leaks is important. The mask seal is checked by performing an occlusion test and recording tidal breathing for $\sim 30 \mathrm{~s}$, followed by a high-volume (end-inspiratory) 1-s airway occlusion, with at least five breaths following the occlusion to allow restabilization of the EEL [16]. Loss of airway opening pressure during the occlusion and/or a step-up in volume following release of the occlusion usually indicates a leak around the face mask (or tracheal tube); in which case it should be adjusted and the measurement repeated. Flow through the PNT during such an occlusion may indicate a leak through the occlusion valve (or an inadequately balanced PNT); in which case attempts should be made to adjust or recalibrate the PNT. It should be noted that many investigators remove the mask between measurements. If this procedure is followed, the operator must ensure that an adequate seal is achieved for each measurement; however, performing an occlusion test before each measurement is not practical. 6) Prior to the first manoeuvre, $\sim 30 \mathrm{~s}$ of tidal breathing should be recorded, and this repeated later, if necessary, to provide a measure of resting tidal breathing and stability of EEL, and some indication regarding sleep state.

\section{Determination of optimal jacket pressure}

The following procedure is presented as a guide. Depending on the type of jacket used, efficacy of pressure transmission, and the age and clinical status of the infant, operators should use their discretion to achieve optimal $P \mathrm{j}$ as rapidly as possible, with the least number of manoeuvres. For example, in healthy infants, some operators commence with $P \mathrm{j}$ at $5 \mathrm{kPa}$, but this would be much too high for sick or very small infants. 1) Use an initial $P \mathrm{j}$ of $2-3 \mathrm{kPa}\left(20-30 \mathrm{cmH}_{2} \mathrm{O}\right)$ (depending on jacket efficiency) with the aim of initially transmitting $\sim 1 \mathrm{kPa}\left(10 \mathrm{cmH}_{2} \mathrm{O}\right)$ to the pleural space (see Measurement of efficacy of jacket pressure transmission section). 2) Perform a single squeeze manoeuvre at end inspiration, ensuring that the jacket remains inflated throughout the entire expiration, and determine flow at FRC, $\left(V^{\prime}\right.$ FRC) (on-line analysis, or cursor placement on screen). 3) Increase $P \mathrm{j}$ in 1-2-kPa increments (depending on jacket efficiency, and infant's clinical status) until the optimal pressure appears to have been achieved, defined as the lowest pressure required to achieve $V^{\prime}$ max,FRC. 4) Perform three squeezes at the first estimate of optimal pressure and at one pressure increment above and below this pressure to confirm the lowest pressure at which the highest flows are obtained. This pressure should then be used throughout the study (including after therapeutic interventions). 5) Reassess optimal $P$ if experimental conditions change. However, although this may be feasible after administration of a bronchodilator, when somewhat higher pressures may elicit higher flows, during bronchial challenge the situation is more complex since there is no time to reassess the optimal $P \mathrm{j}$ between doses. Regrettably, considerable further research is required before clear recommendations can be produced with respect to standardizing assessments of bronchial responsiveness in infants.

\section{Measurement efficacy of jacket pressure transmission}

This can be performed either dynamically (using oesophageal manometry) or statically (by performing airway occlusion immediately prior to jacket inflation) $[9,17,18]$. Since relatively few laboratories perform routine oesophageal manometry, the use of the simpler static occlusion manoeuvre for estimation of jacket efficiency is recommended for general use [4].

In order to perform this manoeuvre, the airway opening is briefly occluded at end inspiration, followed by jacket inflation using the optimal $P_{\mathrm{j}}$ [9]. The change in airway pressure during jacket inflation (above that recorded at end inspiration due to the elastic recoil pressure, $P$ ao,j) represents the amount of pressure transmitted to the intrathoracic structures at end inspiration during the squeeze $[17,18]$. $P$ ao,j should generally be $\geq 2 \mathrm{kPa}$, except in infants with marked airway obstruction, in whom flow dependence is achieved at lower pressures.

This manoeuvre should be repeated up to three times, with the results reported both as the absolute and the mean percentage $P$ j transmitted to the airway opening. Although 
this is considered by some to be an optional quality control measure, some method of assessing relative jacket efficiency (which can range $20-70 \%$ ) is essential if data are to be compared within and between centres.

\section{Collection of maximal flow at functional residual capacity data}

The following protocol is presented as a guide in an attempt to standardize data collection in order to aid international comparison of data. It has been developed by consensus amongst experienced investigators. It is not meant to represent the only way of measuring $V^{\prime} \max$,FRC. These guidelines will need to be updated periodically. 1) Verify tidal loops are stable, i.e. regular breathing pattern; absence of drift, leaks, etc. 2) Verify stable EEL. This could be achieved by overlaying the tidal curves or by calculation of deviations from the end expiratory baseline. A preliminary suggestion is that, after dedrifting of the volume signal and establishing a mean EEL from 5-10 breaths preceding the squeeze, the sd of this EEL (EELsd) should not exceed $0.3 \mathrm{~mL} \cdot \mathrm{kg}^{-1}$. Alternatively, the stability of the EEL could be expressed as a percentage with respect to the infant's tidal volume $(V \mathrm{~T})\left(\mathrm{EELSD}, \% V_{\mathrm{T}}\right.$; (EELSD/mean $V \mathrm{~T}) \times 100$ ), aiming for a value of $<3 \%$. The usefulness and feasibility of achieving these criteria needs further clarification. 3) Ensure that the inspired volume of the breath preceding the squeeze is within $5 \%$ of the previous five breaths (e.g. for an infant with a mean $V \mathrm{~T}$ of $60 \mathrm{~mL}$ prior to the RTC, the inspired volume immediately preceding the RTC should fall by $57-63 \mathrm{~mL}$ ). Further research is required to establish the influence of variability of breath size on $V^{\prime}$ max,FRC. 4) Inflate jacket at end-tidal inspiration. 5) Maintain inflation throughout the entire forced expiration. As a default safety measure, release inflation after $2 \mathrm{~s}$ if no inspiratory effort is made. 6) Verify acceptability of curve using the following criteria: peak flow occurring within the first $30 \%$ of the volume of the previous tidal breath (unless there is a fixed upper airway obstruction, in which case this may not apply); curve continuing past previous stable FRC (i.e. EEL), with no evidence of early inspiratory effort (i.e. sudden sharp fall in flow); and absence of glottic closure, particularly in the last $50 \%$ of expiration. It should be noted that the latter criteria should not result in automatic discarding of data, but should result in a warning alerting the user to potential problems, and the choice as to whether to discard or retain, depending on their magnitude. Further opportunities for quality control should be available during off-line analysis, when there is more time to make such decisions.

\section{Calculations}

\section{Tidal breathing parameters}

See also the document describing tidal breathing analysis [13]. Tidal breathing parameters include EEL, $V \mathrm{~T}$ and respiratory frequency $(f \mathrm{R})$. Establishment of a representative EEL is crucial to the accuracy of the $V^{\prime}$ max,FRC measurements. 1) The EEL (i.e. FRC) should be established over at least five breaths (preferably 10) prior to the squeeze, after correcting for any volume drift. In young infants with less regular breathing patterns, such calculations may need to be performed over a larger number of breaths (user-defined). 2) For consistency, it is suggested that the EEL is calculated as the mean of all selected end-expiratory points after dedrifting, and that the selected level is clearly displayed on a time-based trace for verification of accuracy by the operator. Some user flexibility may be required in those cases in which EEL is particularly variable.

\section{Forced expiration}

The best algorithm to employ for calculation of $V^{\prime}$ max,FRC is still open to discussion. At this stage, interpolation between flows would appear to be the most suitable option for computerized implementation. The mean $V^{\prime}$ max,FRC should be calculated from five technically acceptable curves (minimum three).

\section{Quality control parameters}

Although $V^{\prime} \max , \mathrm{FRC}$ is the only "outcome measure" that is routinely reported from the RTC technique, numerous other calculations are required for quality control, and to allow comparison of data within and between centres. The parameters that should be displayed/available for each individual trial to assist in user- or automated selection of the "best" data and to provide overall quality assurance are listed below. Since many of these quality control features need to be reported in publications describing $V^{\prime}$ max,FRC measurements in infants, it is essential that such information can be automatically saved and, if required, exported to a suitable spreadsheet.

The use of standard abbreviations, as indicated below, would be of enormous benefit and is strongly recommended.

Quality control and other parameters include: 1) number of acceptable manoeuvres (n); 2) total number of manoeuvres performed (ntot); 3) $P \mathrm{j}$ (in kilopascals), calculated for each trial and presented as the mean; note that $P \mathrm{j}$ should be calculated from the plateau attained and not from the maximum value recorded, which may simply represent a brief transient; 4) $P$ ao,j; 5) pressure (\%) transmitted from the jacket to the airway opening $(\mathrm{P} \% \mathrm{tr}) ; 6)$ apparatus dead space ( $V$ D,app; in millilitres); 7) type of mask, e.g. Rendell Baker size $1 ; 8)$ mean $V$ T prior to squeeze (in millilitres); 9) mean $f R$ prior to squeeze (in breaths $\cdot \mathrm{min}^{-1}$ ); 10) stability of EEL prior to RTC, expressed as EELSD,\% $V \mathrm{~T}$ ) (see Collection of maximal flow at functional residual capacity data section); 11) stability of EEL prior to RTC, expressed as EELSD, (in millilitres); 12) expired volume during forced expiration $(V \mathrm{FE}$; in millilitres); 13) volume expired below FRC during forced expiration $(V \mathrm{E}-\mathrm{FRC}$; in millilitres); 14) jacket compression time (tcomp; in milliseconds), i.e. the time that the jacket is inflated and compresses the chest and abdomen; 15) jacket rise time (trise; in milliseconds); 16) jacket lead time tlead; in milliseconds); 17) duration of forced expiration ( $t \mathrm{FE}$; in seconds); 18) peak expiratory flow (PEF; in $\left.\mathrm{mL} \cdot \mathrm{s}^{-1}\right) ; 19$ ) volume expired at PEF (VPEF; in millilitres); 20) $V \mathrm{PEF}$ as percentage of mean $V \mathrm{~T}$ preceding the RTC $(V \mathrm{PEF}, \% V \mathrm{~T})$; and 21$)$ maximal expired flow when $\mathrm{x} \%$ of the previous $V$ T remains in the 
lung during the RTC $\left(\mathrm{MEFx}_{0} V \mathrm{~T}\right.$; in $\left.\mathrm{mL} \cdot \mathrm{s}^{-1}\right)$; this is currently used by some systems, although still to be validated for use in infants. The version of the software with which the data were collected should also be reported (Vsw).

\section{Reporting}

1) $V^{\prime} \max$,FRC should be reported as the absolute value in $\mathrm{mL} \cdot \mathrm{s}^{-1}$ (no further correction to BTPS is required as this represents an expired flow). 2) The best (i.e. highest flow from technically acceptable curves (see above)) value should be reported, provided it is within $10 \%$ or $10 \mathrm{~mL} \cdot \mathrm{s}^{-1}$ (whichever is greater) of the next highest value. 3) The mean \pm SD or coefficient of variation $(100 \mathrm{sD} /$ mean $)$ of three to five technically satisfactory curves should also be available as a measure of the intrasubject variability. 4) A printout of the best partial expiratory flow/volume curve should be provided. 5) Ideally, data should not be presented as a percentage of the predicted value. Although this has been widely used in the past, it should be avoided since there is a very wide range of "normality" for $V^{\prime} \max , F R C$, which may span $40-200 \%$ pred for an infant of any given weight/length/age. In the interim period, before sufficient data have been collated to establish Z scores, it is suggested that results be expressed in relation to the "normal range" according to the infant's age and sex (see Appendix). 5) If participating in multicentre trials, each individual laboratory should ensure that appropriate reference data are available for their population and that their equipment produces appropriate values using the Standard Equipment Assessment System that is currently being developed by the task force.

\section{Appendix: reference data}

Both manufacturers and users need to be aware that no generally valid reference values are currently available for any infant lung function test. Although many research groups have reported so-called "normative data", this is generally only applicable to their specific population (bearing in mind ethnic, social and age-related factors) and equipment and the type of respiratory function test used.

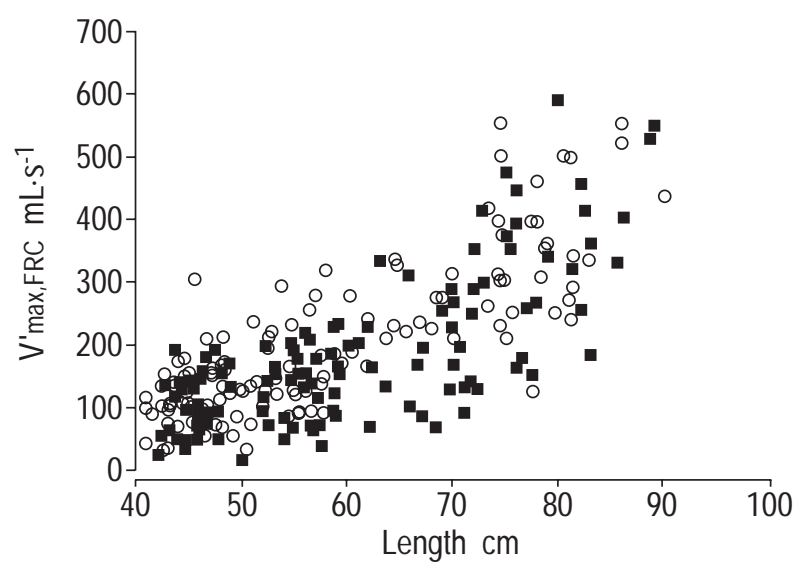

Fig. 1. - Maximal flow at functional residual capacity $\left(V^{\prime} \max , \mathrm{FRC}\right) v e r-$ sus crown-heel length in infants. $\square$ : males; $\bigcirc$ : females. (Data from $[8$, 19, 20].)

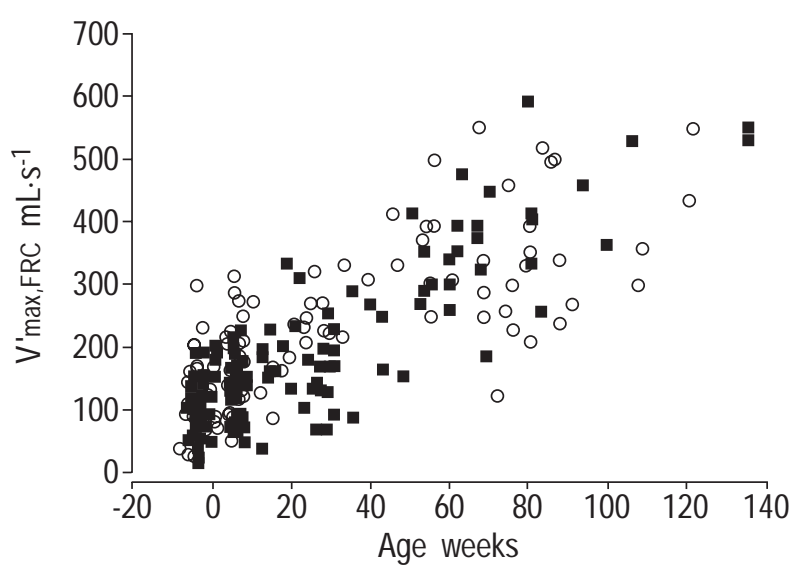

Fig. 2. - Maximal flow at functional residual capacity ( $V^{\prime}$ max,FRC) versus age in infants. $\square$ : males; $\bigcirc$ : females. (Data from $[8,19,20]$.)

Problems may also arise when interpreting serial or longitudinal studies in individuals or groups of individuals: most reference data in this field are based on single rather than serial measurements within individuals. Using crosssectional data to interpret longitudinal data may be misleading, as the centiles derived from cross-sectional data are not a reflection of how an individual changes with time. The way to solve some of these problems in the future may be to pool data between centres that have employed similar techniques, equipment and software. However, it must be kept in mind that differences between centres with respect to populations and precise methodology may still limit the potential value of this approach unless considerable effort is made to take such factors into account.

As a preliminary first approach, data from 279 infants studied by TEPPER et al. [8], and STOCKS and coworkers $[19,20]$, including some delivered prematurely, have been pooled. No interlaboratory differences were detected in the relationship between $V^{\prime} \max , \mathrm{FRC}$ and age or body size, although the majority of the younger and preterm infants were studied in London, UK by STOCKS and coworkers $[19,20]$ and the majority of the older infants were studied by TEPPER et al. [8] in Indianapolis, IN, USA. The postnatal age ranged 1-139 weeks, corrected

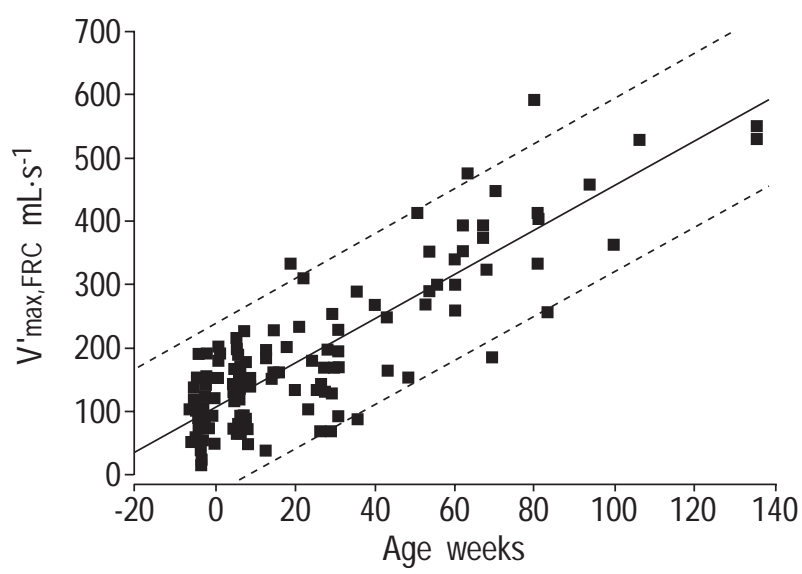

Fig. 3. - Maximal flow at functional residual capacity ( $V^{\prime}$ max,FRC) versus age in male infants. - : line of regression ( $V^{\prime}$ max,FRC $=114 \pm$ $7.1+$ corrected postnatal age $\times 3.4 \pm 0.19 ; \mathrm{r}^{2}=0.72($ mean \pm SEM $\left.)\right) ;---: 95 \%$ confidence interval. (Data from $[8,19,20]$.) 


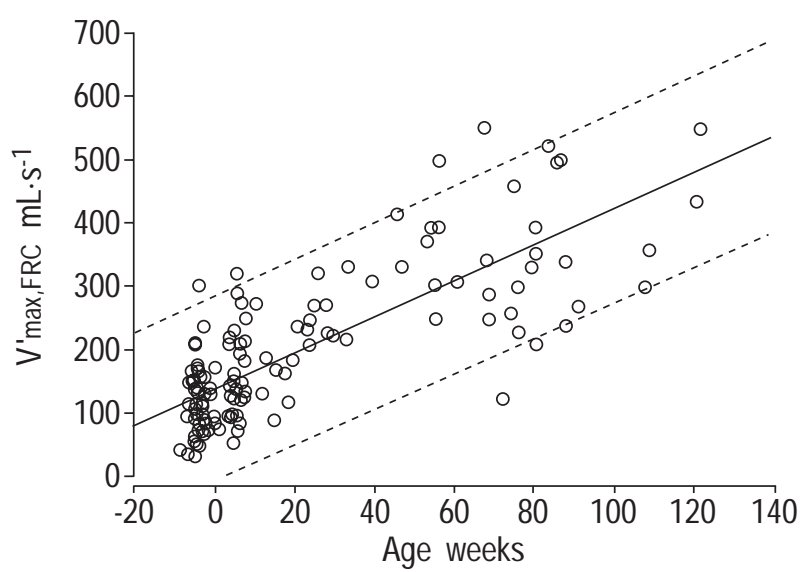

Fig. 4. - Maximal flow at functional residual capacity $\left(V^{\prime} \max , \mathrm{FRC}\right)$ versus age in female infants. - : line of regression $\left(V^{\prime}\right.$ max, FRC $=136 \pm$ $7.0+$ corrected postnatal age $\times 2.9 \pm 0.19 ; \mathrm{r}^{2}=0.63($ mean \pm SEM $\left.)\right) ;---: 95 \%$ confidence interval. (Data from $[8,19,20]$.)

postnatal age (taking gestational age into account) -4-139 weeks (term was taken to be 40 weeks gestational age) and crown-heel length 40-90 cm. The relationship between $V^{\prime}$ max,FRC and both weight and length was found to be markedly nonlinear (fig. 1), thereby precluding any simple linear regression analysis. Furthermore, significant sex differences were apparent, with female infants tending to have higher flows than male infants, especially during the first months of life. The simplest "best fit" was found to be that of $V^{\prime}$ max,FRC to age after taking the sex of the infant into account (figs. 2-4). This explained $72 \%$ of the between-subject variation in male infants, and $63 \%$ in the females infants. In order to emphasize the wide range of "normal values" 95\% confidence intervals are also shown (table 2), it should be noted that, amongst infants of $<5$ weeks of age, these encompass zero flow, making it impossible to identify abnormally or unusually low flows in the neonatal period. It is hoped that further data will become available in the near future, allowing more complex modelling and production of appropriate Z scores. In the meantime, the following very preliminary equations are included as a rough guide to the expected $V^{\prime}$ max,FRC range at any given age (mean \pm SEM). It should be noted that the reference sample used to obtain these equations is very provisional due to its uneven age distribution and small size. Extreme caution is therefore required when using these values to interpret individual results for the reasons summarized in the Reporting section. Male infants $\left(\mathrm{n}=130 ; \mathrm{r}^{2}=0.72\right): V^{\prime} \max , \mathrm{FRC}=114 \pm 7.1+$ postnatal age $\times 3.4 \pm 0.19$, and female infants $\left(n=149 ; r^{2}=0.63\right)$ : $V^{\prime} \max , \mathrm{FRC}=136 \pm 7.0+$ postnatal age $\times 2.9 \pm 0.19$, where the

Table 2. - Examples of "normal" maximal flow at functional residual capacity ( $V$ max,FRC) ranges in infants at various corrected postnatal ages*

\begin{tabular}{lccc}
\hline & \multicolumn{3}{c}{$V^{\prime} \max , \mathrm{FRC} \mathrm{mL} \cdot \mathrm{s}^{-1}$} \\
\cline { 2 - 4 } Sex & 5 weeks & 6 months & $1 \mathrm{yr}$ \\
\hline Males & $0-260$ & $70-330$ & $160-420$ \\
Females & $0-300$ & $60-360$ & $140-440$ \\
\hline
\end{tabular}

*: taking gestational age into account. postnatal age is the corrected postnatal age in weeks and the result is expressed in $\mathrm{mL} \cdot \mathrm{s}^{-1}$.

\begin{abstract}
Acknowledgements. The authors would like to thank all members of the Task Force who contributed to developing these recommendations, particularly E. BarYishay (Jerusalem, Israel), C. Beardsmore (Leicester, UK), R. Castile (Columbus, OH, USA), J.B. Clough (Southampton, UK), I. Dundas (London, UK), S. Godfrey (Jerusalem, Israel), R. Gregson (Southampton, UK), P. Gustafsson (Skövde, Sweden), A-F. Hoo (London, UK). P. Merkus (Rotterdam, the Netherlands), M. Morris (Little Rock, AR, USA), D. Vilozni (Petach Tikva, Israel), E. van der Weil (Rotterdam, the Netherlands) who reviewed the various drafts of this manuscript and provided invaluable feedback.
\end{abstract}

\section{References}

1. American Thoracic Society/European Respiratory Society. Respiratory mechanics in infants: physiologic evaluation in health and disease. Am Rev Respir Dis 1993; 147: 474-496.

2. Beardsmore CS, Godfrey S, Silverman M. Forced expiratory flow-volume curves in infants and young children. Eur Respir J 1989; 2: Suppl. 4, 154s-159s.

3. Le Souëf PN, Hughes DM, Landau LI. Shape of forced expiratory flow-volume curves in infants. Am Rev Respir Dis 1988; 138: 590-597.

4. Le Souëf PN, Castile R, Motoyama E, Turner D, Morgan W. Forced expiratory maneuvers. In: Stocks J, Sly PD, Tepper RS, Morgan WJ, eds. Infant Respiratory Function Testing. 1st Edn. New York, John Wiley \& Sons, Inc., 1996; pp. 379-410.

5. Morgan WJ, Geller DE, Tepper RS, Taussig LM. Partial expiratory flow-volume curves in infants and young children. Pediatr Pulmonol 1988; 5: 232-243.

6. Stocks J, Sly PD, Tepper RS, Morgan WJ, eds. Infant Respiratory Function Testing. 1st Edn. New York, John Wiley \& Sons, Inc., 1996.

7. Taussig LM, Landau LI, Godfrey S, Arad I. Determinants of forced expiratory flows in newborn infants. $J$ Appl Physiol 1982; 53: 1220-1227.

8. Tepper RS, Reister T. Forced expiratory flows and lung volumes in normal infants. Pediatr Pulmonol 1993; 15: $357-361$.

9. Turner DJ, Morgan SEG, Landau LI, Le Souëf PN. Methodological aspects of flow volume studies in infants. Pediatr Pulmonol 1990; 8: 289-293.

10. England SJ. Current techniques for assessing pulmonary function in the newborn and infant: advantages and limitations. Pediatr Pulmonol 1989; 4: 48-53.

11. Frey U, Stocks J, Sly P, Bates J, on behalf of the ERS/ATS Task Force on Standards for Infant Respiratory Function Testing. Specifications for equipment used for infant pulmonary function testing. Eur Respir J 2000; 16: 729-738.

12. Frey U, Stocks J, Sly P, Bates J, on behalf of the ERS/ATS Task Force on Standards for Infant Respiratory Function Testing. Specifications for signal processing and data handling used for infant pulmonary function testing. Eur Respir J 2000; (in press).

13. Bates JHT, Schmalisch G, Filbrun D, Stocks J, on behalf of the ERS/ATS Task Force on Standards for Infant Respiratory Function Testing. Standards for infant respiratory 
function testing. Tidal breath analysis for infant pulmonary function testing. Eur Respir J 2000; (in press).

14. Miller MR, Sigsgaard T. Prevention of thermal and condensation errors in pneumotachographic recordings of the maximal forced expriatory manoeuvre. Eur Respir $J$ 1994; 7: 198-201.

15. Steinbrugger B, Lanigan A, Raven JM, Olinsky A. Influence of the "squeeze jacket" on lung function in young infants. Am Rev Respir Dis 1988; 138: 1258-1260.

16. Stocks J, Nothen U, Sutherland P, Hatch DJ, Helms P. Improved accuracy of the occlusion technique for assessing total respiratory compliance in infants. Pediatr Pulmonol 1987; 3: 71-77.

17. Turner DJ, Lanteri CJ, Le Souëf PN, Sly PD. Pressure transmission across the respiratory system at raised volumes in infants. $J$ Appl Physiol 1994; 77: 1015-1020.

18. Stick S, Turner D, Le Souëf PN. Transmission of pressure across the chest wall during the rapid thoracic compression technique in infants. $J$ Appl Physiol 1994; 76 : $1411-1416$

19. Hoo A-F, Henschen M, Dezateux C, Costeloe K, Stocks J. Respiratory function among preterm infants whose mothers smoked during pregnancy. Am J Respir Crit Care Med 1998; 158: 700-705.

20. Stocks J, Henschen M, Hoo A-F, Costeloe K, Dezateux $\mathrm{CA}$. The influence of ethnicity and gender on airway function in preterm infants. Am J Respir Crit Care Med 1997; 156: 1855-1862. 